\title{
Effects of Exercise Intervention on Vascular Risk Factors in Older Adults with Mild Cognitive Impairment: A Randomized Controlled Trial
}

\author{
Kazuki Uemura ${ }^{a, c}$ Takehiko Doi ${ }^{a}$ Hiroyuki Shimada ${ }^{a}$ \\ Hyuma Makizako $^{\mathrm{a}, \mathrm{c}}$ Daisuke Yoshida ${ }^{\mathrm{a}}$ Kota Tsutsumimoto $^{\mathrm{a}}$ \\ Yuya Anan ${ }^{a}$ Takao Suzuki ${ }^{b}$ \\ a Section for Health Promotion, Center for Gerontology and Social Science, and \\ ${ }^{b}$ Research Institute, National Center for Geriatrics and Gerontology, Obu, and \\ 'Japan Society for the Promotion of Science, Tokyo, Japan
}

\section{Key Words}

Cholesterol $\cdot$ Rehabilitation $\cdot$ Cognitive impairment $\cdot$ Metabolic profiles $\cdot$ Dementia $\cdot$ Vascular risk factors $\cdot$ Physical activity

\begin{abstract}
Aims: The purpose of this study is to clarify the effects of exercise intervention on vascular risk factors in older adults with mild cognitive impairment (MCl). Methods: Community-dwelling older adults who met the definition of $\mathrm{MCl}$ using the Petersen criteria $(n=100$; mean age $=75.3$ years) were randomly allocated to the exercise $(n=50)$ or education control group $(n=50)$. Participants in the exercise group exercised under the supervision of physiotherapists for $90 \mathrm{~min} /$ day, 2 days/week, 80 times for 12 months. Anthropometric profiles, blood markers, blood pressure, and physical fitness (the 6-min walking test) were measured. Total cholesterol (TC), highdensity lipoprotein cholesterol (HDL-C), and TC/HDL-C risk ratio measurements were taken from blood samples. Results: The exercise group showed significantly reduced TC and TC/HDL-C risk ratio after training compared with baseline levels $(p<0.001, p=0.004)$. However, no significant reduction was found for the control group $(p=0.09, p=0.09)$. Physical fitness also significantly improved after exercise intervention compared with the control group $(p<0.0001)$. Conclusion: Exercise intervention was associated with positive changes in important vascular risk factors related to cognitive decline and vascular disease in older adults with $\mathrm{MCl}$.
\end{abstract}

Copyright ๑ 2012 S. Karger AG, Basel 
Uemura et al.: Effects of Exercise Intervention on Vascular Risk Factors in Older Adults with Mild Cognitive Impairment: A Randomized Controlled Trial

\section{Introduction}

Cognitive problems in older adults range from mild impairment to severe dementia. The transitional stage between normal aging and dementia has been designated as mild cognitive impairment (MCI) [1, 2]. Individuals with MCI have been found to have a 10-15 times higher risk of developing Alzheimer's disease (AD), although up to 40\% will not develop dementia [3]. It is of great importance to recognize and treat patients at the earliest stage of the disease [4]. Recent studies have reported beneficial effects of physical activity or exercise on cognitive health, such as cognitive function [5-7], brain volume, and activation $[8,9]$, in older adults with and without cognitive impairment.

Vascular risk factors, such as hypertension, hypercholesterolemia, and diabetes mellitus, are associated with both the occurrence and progression of AD dementia [10-13]. It has also been found that vascular risk factors increase the risk of MCI $[14,15]$ and the risk of conversion from MCI to AD [16]. Li et al. [16] also reported that treatment (i.e., medication) of vascular risk factors was associated with a reduced risk of $\mathrm{AD}$ dementia, which suggests that active interventions for vascular risk factors might reduce the progression from MCI to AD dementia.

There is a growing body of evidence showing that regular physical activity has therapeutic and protective effects against dementia $[17,18]$ and cardiovascular disease [19] in older adults. Several studies have suggested that aerobic or resistance exercises have positive effects on vascular risk factors in healthy older adults, for example increases in high-density lipoprotein cholesterol (HDL-C) [20] as well as decreases in total cholesterol (TC), TC/HDL risk ratio, and triglyceride (TG) [21-23]. It is possible that improvements of metabolic profiles by exercise may lead to a decrease in the risk of dementia or vascular disease. However, it remains unclear whether exercise intervention affects vascular risk factors in older adults with MCI.

The identification and subsequent management of risk factors at the MCI stage could be an important strategy for preventing and delaying progression to $\mathrm{AD}$. Considering the observed influence of the cardiovascular system and metabolic profile on the risk of developing dementia, it is important to know the potential benefits derived from exercise in terms of metabolomics. The purpose of this study was to investigate the effects of exercise intervention on vascular risk factors in older adults with MCI.

\section{Participants and Methods}

\section{Participants}

In this 12-month randomized controlled trial, subjects were randomly allocated to the exercise or education control group at the end of a baseline assessment. Study personnel involved in the collection of outcome measures were blinded to the randomization assignment. The Ethics Committee of the National Center for Geriatrics and Gerontology (Obu, Japan) approved the study protocol. The purpose, nature, and potential risks of the experiments were fully explained to the subjects, and all subjects gave written informed consent before participating in the study.

Subjects in this study were recruited from our volunteer databases, which included elderly individuals ( 65 years and over). Participants had to be community-dwelling adults aged 65 years and older to be included in the study. A total of 528 prospective subjects with a Clinical Dementia Rating (CDR) of 0.5 [24] or who complained of memory impairment were recruited in the first eligibility assessments. A total of 135 subjects responded to the second eligibility assessments. Thirty-five out of 135 subjects were excluded, and the 100 subjects 
Excluded $(n=1,408)$

No memory complaint

( $n=765$ )

History of stroke ( $n=32)$

History of heart disease

( $n=35)$

Having other medical

problems $(n=14)$

Participating in other

projects $(n=10)$

Not contacted $(n=299)$

$C D R=0(n=150)$

CDR $=1-3(n=100)$

Refuse to participate

$(n=3)$

Excluded $(\mathrm{n}=9)$

Refuse to continue $(n=4)$

Having any medical

problem $(n=5)$
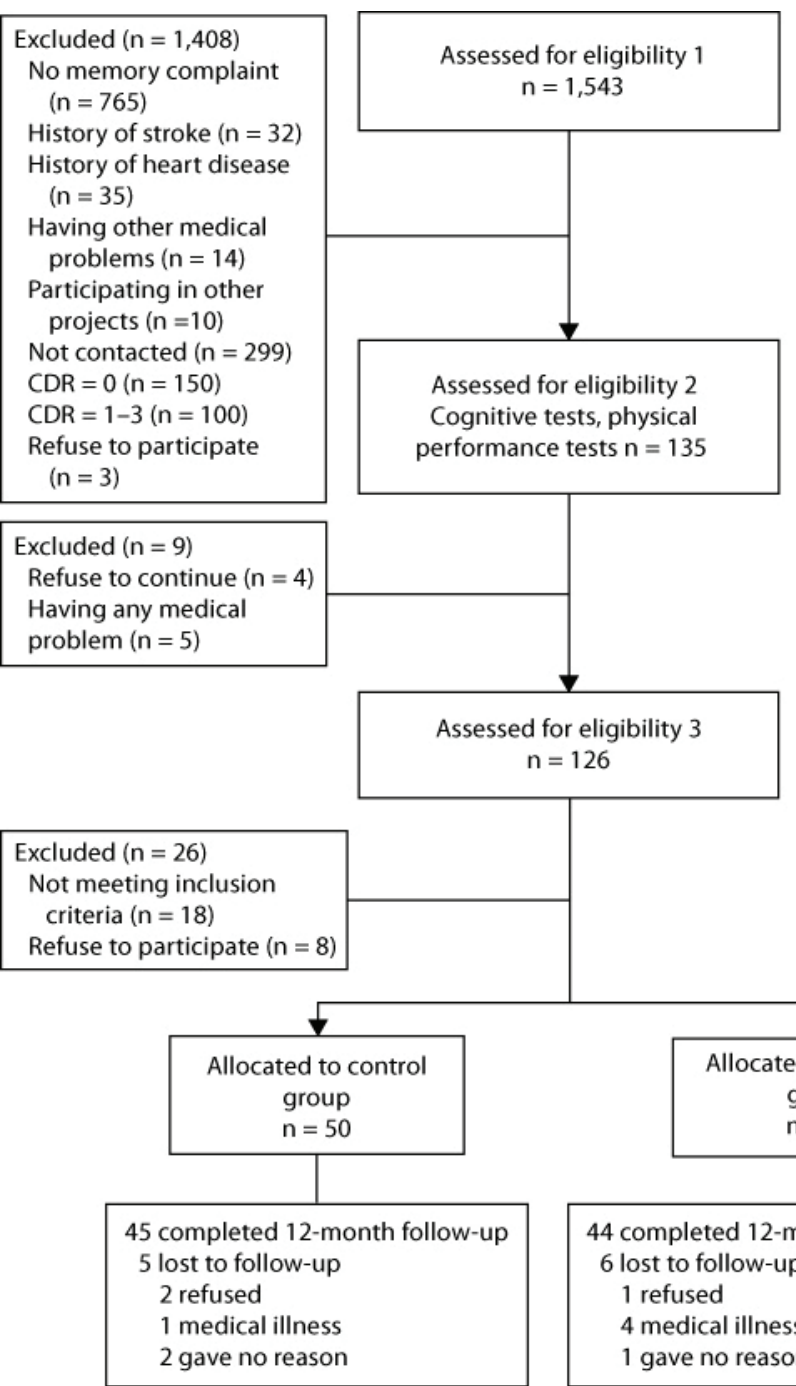

use to participate $(n=8)$

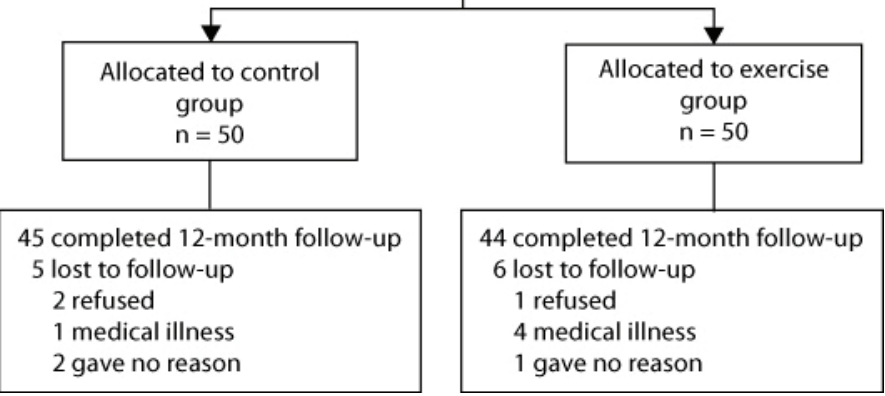

Fig. 1. Subject flow diagram from the initial contact through to study completion.

who remained met the definition of MCI using the Petersen criteria [3]. Exclusion criteria included a CDR of 0 or 1-3, a history of neurological, psychiatric, and cardiac disorders, and other severe health issues (i.e., recent myocardial infarction and unstable angina), uncontrolled hypertension, use of donepezil, impairments in basic activities of daily living, and participation in other research projects.

The Consolidated Standards of Reporting Trials (CONSORT) [25] diagram outlining the subject flow from the first contact to the study completion is shown in figure 1 .

\section{Interventions}

The 12-month exercise program involved biweekly 90-min sessions with aerobic exercise, muscle strength training, postural balance retraining, and combined training. In addition, the exercise program included a focus on promoting exercise and behavior change. Two 
trained physiotherapists involved in geriatric rehabilitation conducted each intervention. Each supervised session began with a 10-min warm-up period and stretching exercise, followed by $20 \mathrm{~min}$ of muscle strength exercise. Then, the participants practiced aerobic exercise, postural balance retraining, and combined training for $60 \mathrm{~min}$. For the aerobic exercise, participants underwent stair stepping and endurance walking. The mean intensity of the aerobic exercise was approximately $60 \%$ of the maximum heart rate.

Before and after each session of the program, the physiotherapists conducted a physical check of each participant. The participants were required to carry out daily home-based muscle strength exercises and walking, which were self-monitored using a booklet and pedometer based on the concept of promoting exercise and behavior change.

Subjects in the education control group attended three education classes about health promotion during the 12-month study period. The classes provided information regarding aging, healthy diet, oral care, brain image diagnosis, prevention of urinary incontinence, and health checks. However, the group did not receive specific information regarding exercise, physical activity, or cognitive health.

\section{Anthropometry}

Anthropometric measurements were obtained while the subjects were dressed in light clothing without shoes. Height (to the nearest $0.1 \mathrm{~cm}$ ) and body weight (to the nearest $0.1 \mathrm{~kg}$ ) were recorded. The body mass index (BMI) was calculated using the standard formula: weight $(\mathrm{kg}) /\left[\right.$ height $\left.(\mathrm{m})^{2}\right]$.

\section{Blood Markers and Blood Pressure}

TC, HDL-C, TG, and glycosylated hemoglobin (HbAlc) were measured from blood samples, which were collected between 11 a.m. and 4 p.m. in a non-fasting state. The blood samples were kept at room temperature for $30 \mathrm{~min}$ to allow for clotting, then the samples were centrifuged for $15 \mathrm{~min}$. Serum was harvested and stored at $-25^{\circ} \mathrm{C}$ until analysis. Analyses were carried out centrally in one laboratory (Special Reference Laboratories, Tokyo, Japan). Serum samples were analyzed for TC, HDL-C, TG, and HbAlc. The TC/HDL-C ratio [26] was calculated as an index of lipid-associated coronary heart disease risk and is supported by both its superior predictive power compared with TC, LDL-C, or HDL-C levels and lower within-person variability [27]. Systolic and diastolic blood pressures were measured using a standard sphygmomanometer in the sitting position after a 5-min rest.

\section{Physical Fitness}

The participants' exercise capacity was quantitatively measured using the 6-min walking test (6MWT). The $6 \mathrm{MWT}$ is used to measure the maximum distance that a person can walk in 6 min [28]. Participants were instructed to walk as far as possible in 6 min along a 10 -meter course, performed under the supervision of a physiotherapist. This study used the distance (in meters) in the 6MWT as a measure of physical fitness.

\section{Statistical Analysis}

Baseline characteristics were compared among groups using Student's t test for quantitative variables and the $\chi^{2}$ test for qualitative variables. The intervention effects on all outcome measures were determined using two-way repeated measures ANOVA, with group (exercise, control) as a between-subjects factor and time (before training, after training) as a within-subjects factor. A probability of $\mathrm{p}<0.05$ was considered statistically significant. Post hoc comparisons were performed to test the differences in physical function variables between before and after the training in each group. The significance level of multiple comparisons was adjusted using the Bonferroni correction ( $\mathrm{p}<0.025 ; 0.05 / 2)$, and analyses were 
Table 1. Baseline characteristics of the study subjects

\begin{tabular}{lccl}
\hline & Exercise $(\mathrm{n}=50)$ & Control $(\mathrm{n}=50)$ & p value (t test) \\
\hline Age, years & $74.8 \pm 7.4$ & $75.8 \pm 6.1$ & 0.46 \\
Men & $25(50)$ & $26(52)$ & $0.84^{\mathrm{a}}$ \\
BMI & $23.4 \pm 3.4$ & $22.9 \pm 3.1$ & 0.52 \\
Educational level, years & $10.9 \pm 2.8$ & $10.3 \pm 2.3$ & 0.29 \\
Number of medications & $2.5 \pm 2.3$ & $2.4 \pm 2.2$ & 0.89 \\
GDS score & $3.8 \pm 3.1$ & $3.3 \pm 2.8$ & 0.38 \\
Physical performance & & & \\
$\quad$ Grip strength, kg & $24.7 \pm 8.1$ & $23.5 \pm 7.3$ & 0.47 \\
$\quad$ Timed up \& go, s & $8.8 \pm 2.5$ & $9.2 \pm 2.1$ & 0.37 \\
Cognitive function & $26.8 \pm 2.3$ & $26.3 \pm 2.7$ & 0.30 \\
$\quad$ MMSE score & $6.0 \pm 2.7$ & $6.5 \pm 2.8$ & 0.37 \\
$\quad$ ADAS-cog score & & & \\
\hline
\end{tabular}

Values are means \pm SD or $n(\%)$. GDS $=$ Geriatric Depression Scale; MMSE $=$ Mini-Mental State Examination; ADAS-cog $=$ Alzheimer's Disease Assessment Scale-cognitive subscale. ${ }^{a} \chi^{2}$ test.

performed using SPSS version 20.0 for Windows (SPSS Inc., Chicago, Ill., USA). To perform the intention-to-treat analysis, a single imputation was used for all outcome measures. Missing data values were estimated using mean values for each corresponding group [29].

\section{Results}

There were no significant differences in baseline characteristics between the exercise and control groups (table 1). Figure 1 shows the flow of participants from the time of screening to study completion at 12 months. Eighty-nine (exercise group, $n=44$ ) subjects completed the 12-month follow-up. The mean adherence to the exercise program was $78.6 \%$, and 34 subjects $(68.0 \%)$ in the exercise group attended our intervention program with more than $80 \%$ adherence.

Table 2 depicts all fitness-related variables for the exercise and control groups before and after the training. No interaction effects between group and time were detected for body weight and BMI $[\mathrm{F}(1,98)=0.6, \mathrm{p}=0.43 ; \mathrm{F}(1,98)=0.4, \mathrm{p}=0.51$, respectively $]$. Both the exercise and control groups showed reduced body weight and BMI after the intervention compared with before the intervention (exercise, $\mathrm{p}<0.001$; control, $\mathrm{p}=0.01$ ).

No interaction effects between group and time were detected for systolic and diastolic blood pressure $[\mathrm{F}(1,98)=1.0, \mathrm{p}=0.31 ; \mathrm{F}(1,98)=3.7, \mathrm{p}=0.06$, respectively]. Both the exercise and control groups showed reduced systolic blood pressure after intervention (exercise, $\mathrm{p}=$ 0.02; control, $\mathrm{p}=0.001$ ), but no significant change in diastolic blood pressure between before and after the intervention was observed in both groups (exercise, $\mathrm{p}=0.09$; control, $\mathrm{p}=0.9$ ).

A statistically significant interaction effect between group and time was found for the TC level $[\mathrm{F}(1,98)=5.1, \mathrm{p}=0.03$; fig. 2a]. Post hoc comparisons revealed that the exercise group had significantly reduced TC levels compared with baseline levels $(\mathrm{p}<0.001)$; however, no significant reduction was found for the control group $(\mathrm{p}=0.09)$. There were no interaction effects between group and time for other blood markers [TC/HDL-C risk ratio, $\mathrm{F}(1,98)=0.77, \mathrm{p}=0.38 ; \mathrm{HDL}-\mathrm{C}, \mathrm{F}(1,98)=0.6, \mathrm{p}=0.25 ; \mathrm{TG}, \mathrm{F}(1,98)=0.2, \mathrm{p}=0.78 ; \mathrm{HbA1}$, $\mathrm{F}(1,98)=0.05, \mathrm{p}=0.36]$. Post hoc comparisons revealed that the exercise group had a significantly reduced TC/HDL-C risk ratio after exercise training compared with before exer- 
Table 2. Fitness-related measurements according to group before and after the intervention (mean \pm SD)

\begin{tabular}{llllll}
\hline & & Before & After & $\begin{array}{l}\text { F-value } \\
\text { 1. time effect } \\
\text { 2. time } \times \text { group }\end{array}$ & $\begin{array}{l}\text { Partial } \eta^{2} \\
\text { 1. time effect } \\
\text { 2. time } \times \text { group }\end{array}$ \\
& & & & & \\
Anthropometry & & & & & \\
Body weight, kg & exercise group & $56.2 \pm 9.6$ & $55.2 \pm 8.9^{* *}$ & $19.7^{\dagger \dagger}$ & 0.17 \\
& control group & $54.2 \pm 8.8$ & $53.5 \pm 8.7^{*}$ & 0.6 & 0.006 \\
BMI & exercise group & $23.4 \pm 3.3$ & $22.9 \pm 3.1^{* *}$ & $19.7^{\dagger \dagger}$ & 0.17 \\
& control group & $22.8 \pm 3.1$ & $22.5 \pm 3.0^{*}$ & 0.4 & 0.004 \\
\hline Blood pressure & & & & & \\
Systolic, mm Hg & exercise group & $144.6 \pm 21.6$ & $138.4 \pm 20.3^{*}$ & $17.8^{\dagger \dagger}$ & 0.15 \\
& control group & $142.4 \pm 19.4$ & $132.5 \pm 17.5^{* *}$ & 1.0 & 0.01 \\
Diastolic, mm Hg & exercise group & $74.6 \pm 11.7$ & $77.9 \pm 11.1$ & 0.24 & 0.014 \\
& control group & $75.1 \pm 11.2$ & $74.3 \pm 9.2$ & 3.7 & 0.036 \\
\hline Blood markers & & & & & \\
TC, mg/dl & exercise group & $211.7 \pm 36.2$ & $193.6 \pm 28.1^{* *}$ & $19.3^{\dagger \dagger}$ & 0.16 \\
& control group & $200.5 \pm 34.6$ & $194.7 \pm 31.0$ & $5.1^{\dagger}$ & 0.05 \\
TC/HDL-C risk ratio & exercise group & $3.9 \pm 1.0$ & $3.7 \pm 1.0^{* *}$ & $10.8^{\dagger \dagger}$ & 0.1 \\
& control group & $3.8 \pm 0.9$ & $3.7 \pm 0.8$ & 0.38 & 0.008 \\
HDL cholesterol, mg/dl & exercise group & $57.5 \pm 16.0$ & $55.6 \pm 14.6$ & 0.3 & 0.01 \\
& control group & $55.1 \pm 13.2$ & $55.2 \pm 12.5$ & 0.25 & 0.01 \\
TG, mg/dl & exercise group & $129.2 \pm 64.7$ & $131.8 \pm 57.4$ & 0.007 & 0 \\
& control group & $138.5 \pm 91.5$ & $134.7 \pm 69.9$ & 0.21 & 0.002 \\
HbA1c, \% & exercise group & $5.6 \pm 0.8$ & $5.6 \pm 0.9$ & 1.1 & 0.01 \\
& control group & $5.4 \pm 0.5$ & $5.4 \pm 0.4$ & 0.05 & 0.001 \\
\hline Physical fitness & & & & & \\
6MWT distance, m & exercise group & $378.0 \pm 78.4$ & $445.9 \pm 97.8^{* *}$ & $81.5^{\dagger \dagger}$ & 0.45 \\
& control group & $363.5 \pm 63.0$ & $402.9 \pm 70.7^{* *}$ & $5.7^{\dagger}$ & 0.06 \\
\hline
\end{tabular}

* Significant difference between before and after the training within the group (Bonferroni, $\mathrm{p}<0.025)$. ** Significant difference between before and after the training within the group (Bonferroni, $\mathrm{p}<0.005$ ). ${ }^{\dagger \dagger} \mathrm{p}<0.01 ;{ }^{\dagger} \mathrm{p}<0.05$

cise training ( $\mathrm{p}=0.004)$, but no significant reduction was found for the control group $(\mathrm{p}=$ 0.09). There were no significant changes in HDL-C, TG, and HbAlc between before and after the intervention in both the exercise and control groups.

6MWT, our measure of physical fitness, showed significant interaction effects between group and time $[\mathrm{F}(1,98)=5.7, \mathrm{p}=0.02$; fig. $2 \mathrm{~b}]$ and was significantly increased in both the exercise and control groups compared with before the intervention (exercise, $\mathrm{p}<0.001$; control, $\mathrm{p}<0.001)$.

\section{Discussion}

This study found that exercise intervention resulted in positive changes of blood markers, namely TC and TC/HDL-C levels, among older adults with MCI. Our baseline values were normal for TG and HDL-C, and borderline high for TC [30]. Numerous studies have shown that exercise improves lipid profiles among older adults. Indeed, a meta-analysis concluded that exercise could improve lipid profiles, including reducing TC and TC/HDL-C levels [31]. The multicomponent exercises in our intervention involved mainly aerobic exer- 


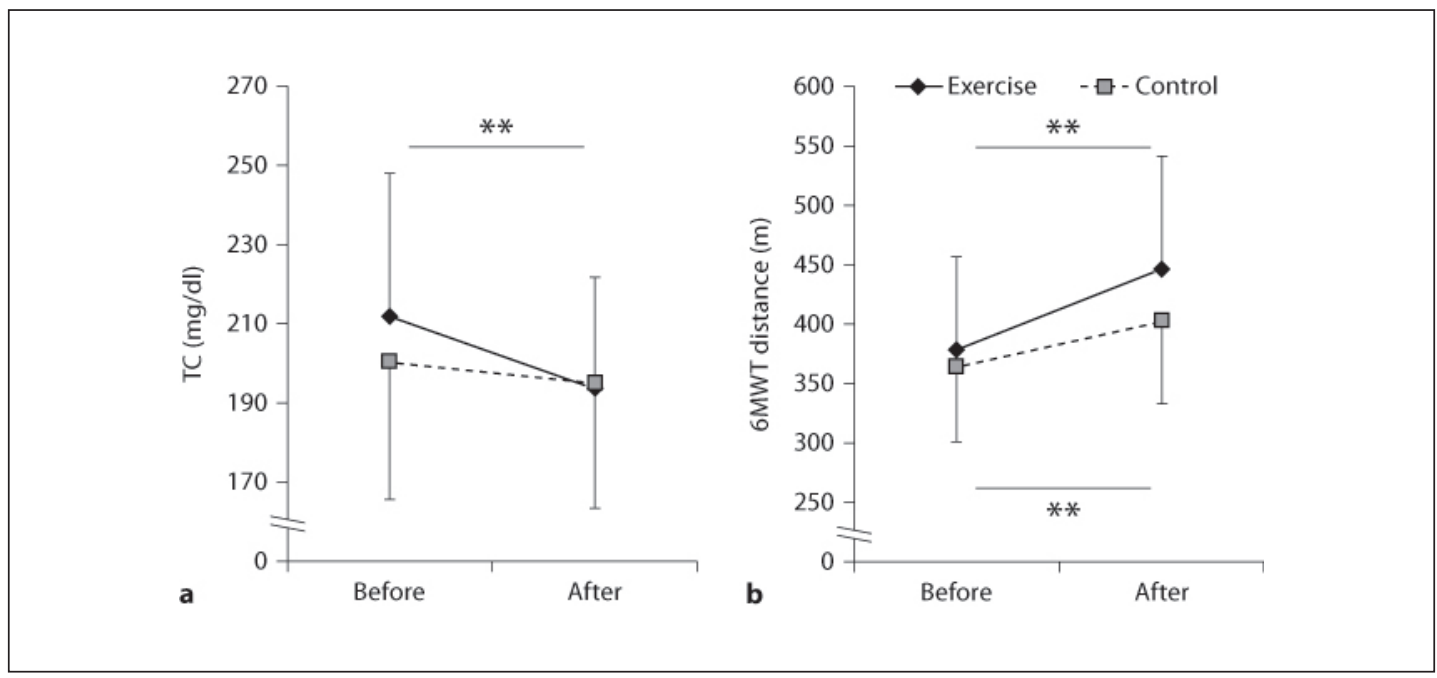

Fig. 2. The average values of TC (a) and 6MWT distance (b) in the exercise and control groups before and after the intervention. ${ }^{* *}$ Significant difference between before and after the training within the group (Bonferroni post hoc test, $\mathrm{p}<0.005$ ).

cise. This type of exercise has been suggested to have positive effects on lipid profiles among older adults with coronary artery disease [32] or type 2 diabetes [33] as well as among healthy older adults [34]. Our study is the first to reveal the effectiveness of exercise intervention on vascular risk factors in older adults with cognitive impairment. Moreover, cardiorespiratory fitness also improved as a result of the increase in the 6MWT distance after exercise intervention, which is in line with previous studies reporting that exercise intervention improved cardiorespiratory functionality in healthy older adults, potentially counteracting the documented age-related decline in peak oxygen uptake $[22,23]$. Previous studies have reported associations between habitual physical activity levels, increased endurance capacity, and/or chronic exercise programs and improvements in lipoprotein profiles in elderly subjects [35, 36]. In the present study, improved cardiorespiratory fitness might contribute to increased physical activity and positive changes in lipid metabolism.

From a metabolomic point of view, exercise intervention may be useful for dementia prevention in older adults with MCI. It has been reported that higher serum levels of TC lead to future cognitive decline and risk of cognitive impairment $[37,38]$. It has also been reported that hypercholesterolemia independently increases the risk of conversion from MCI to $\mathrm{AD}$ [16]. Improved cardiorespiratory fitness and lipid metabolism may prevent vascular pathologies such as atherosclerosis. Furthermore, cholesterol is known to interact with, and modulate the generation of, $A \beta$, which alters cholesterol dynamics in neurons leading to tauopathy [39]. In addition, hypercholesterolemia promotes $A \beta$ production by activating the activity of $\beta$ - and $\gamma$-secretases [40]. The increased $A \beta$ burden resulting from hypercholesterolemia may ultimately promote the development of $\mathrm{AD}$ [16]. The A $\beta$-modulating role of cholesterol may contribute to cognitive dysfunction, although conclusive evidence of the pathophysiological mechanism in dyslipidemias has not been provided yet [39]. In the current study, we also found that decreased TC levels were associated with an improvement in logical memory scores after exercise intervention [unpubl. data]. Therefore, exercise intervention may prevent cognitive decline and the incidence of dementia in older adults with MCI by improving cholesterol metabolism and risk factors (i.e., TC and TC/HDL-C levels) in older adults with MCI. 
Cholesterol is not only a risk factor for cognitive impairment, but is also regarded as a vascular risk factor in such diseases as coronary heart disease and cerebrovascular disease [41]. It has been reported that TC is positively associated with ischemic heart disease mortality in both middle- and old-aged patients [42]. Independent of the mechanism underlying lipid changes, a reduction of $1 \%$ in TC level has been shown to reduce the risk for coronary artery disease by $2 \%$ [43], which implies that our exercising participants have reduced their risk of coronary artery disease by approximately $17 \%$. Additionally, there is a growing body of evidence showing that regular physical activity has therapeutic and protective effects against cerebrovascular disease in older adults [19]. Exercise intervention may have the potential to prevent incidences of vascular disease and related mortality in older adults with MCI. Overall, exercise is a beneficial and inexpensive practice that is associated with numerous benefits for cognitive and metabolic health with minimal adverse effects.

\section{Study Limitations}

There are several limitations to the current study. First, blood samples were collected in a non-fasting state. Although it has been reported that lipoprotein and apolipoprotein levels are not considerably different between fasting and non-fasting states, with the exception of TG, a fasting sample is preferred for precise assessment and management of cardiovascular risk [44]. Second, the intervention of this study lacked nutrient intake assessment and dietary control. It is possible that changes in nutrient intake contributed to decreases in body weight, systolic blood pressure in both groups, and unchanged HDL-C levels, which have been shown to decrease with low total and saturated fat diets [45]. To ascertain that the observed changes were due to exercise rather than other possible factors, a randomized controlled trial with control of nutrient intake in older adults with cognitive impairment and abnormal metabolic profiles, such as metabolic syndrome, should be conducted.

\section{Conclusions}

We investigated the effects of exercise intervention on vascular risk factors in older adults with MCI. The main finding of this study is that exercise intervention reduced TC levels and TC/HDL-C risk ratios among older adults with MCI. Reduction of these vascular risk factors may contribute to reduced cognitive decline and prevention of dementia, vascular disease, and related mortality in the future.

\section{Acknowledgements}

We would like to thank the Obu city office for helping with participant recruitment, and the speech therapists of the Ukai Rehabilitation Hospital for their assistance with data collection. This work was supported by a grant from the Japanese Ministry of Health, Labour, and Welfare (programs minimizing long-term care B-3 to T.S.).

\section{Disclosure Statement}

The authors have no conflict of interest to declare. 
Uemura et al.: Effects of Exercise Intervention on Vascular Risk Factors in Older Adults with Mild Cognitive Impairment: A Randomized Controlled Trial

\section{References}

-1 Petersen RC, Doody R, Kurz A, Mohs RC, Morris JC, Rabins PV, Ritchie K, Rossor M, Thal L, Winblad B: Current concepts in mild cognitive impairment. Arch Neurol 2001;58:1985-1992.

-2 Luck T, Luppa M, Briel S, Riedel-Heller SG: Incidence of mild cognitive impairment: a systematic review. Dement Geriatr Cogn Disord 2010;29:164-175.

-3 Petersen RC: Mild cognitive impairment as a diagnostic entity. J Intern Med 2004;256:183-194.

4 Morris JC, Storandt M, Miller JP, McKeel DW, Price JL, Rubin EH, Berg L: Mild cognitive impairment represents early-stage Alzheimer disease. Arch Neurol 2001;58:397-405.

5 Angevaren M, Aufdemkampe G, Verhaar HJ, Aleman A, Vanhees L: Physical activity and enhanced fitness to improve cognitive function in older people without known cognitive impairment. Cochrane Database Syst Rev 2008:CD005381.

-6 van Uffelen JG, Chin APMJ, Hopman-Rock M, van Mechelen W: The effects of exercise on cognition in older adults with and without cognitive decline: a systematic review. Clin J Sport Med 2008;18: $486-500$.

-7 Smith PJ, Blumenthal JA, Hoffman BM, Cooper H, Strauman TA, Welsh-Bohmer K, Browndyke JN, Sherwood A: Aerobic exercise and neurocognitive performance: a meta-analytic review of randomized controlled trials. Psychosom Med 2010;72:239-252.

8 Voss MW, Prakash RS, Erickson KI, Basak C, Chaddock L, Kim JS, Alves H, Heo S, Szabo AN, White SM, Wojcicki TR, Mailey EL, Gothe N, Olson EA, McAuley E, Kramer AF: Plasticity of brain networks in a randomized intervention trial of exercise training in older adults. Front Aging Neurosci 2010;2:32.

-9 Erickson KI, Voss MW, Prakash RS, Basak C, Szabo A, Chaddock L, Kim JS, Heo S, Alves H, White SM, Wojcicki TR, Mailey E, Vieira VJ, Martin SA, Pence BD, Woods JA, McAuley E, Kramer AF: Exercise training increases size of hippocampus and improves memory. Proc Natl Acad Sci USA 2011;108:3017-3022.

-10 Broderick DF, Schweitzer KJ, Wszolek ZK: Vascular risk factors and dementia: how to move forward? Neurology 2009;73:1934-1935.

-11 de la Torre JC: Is Alzheimer's disease a neurodegenerative or a vascular disorder? Data, dogma, and dialectics. Lancet Neurol 2004;3:184-190.

-12 Li J, Zhang M, Xu ZQ, Gao CY, Fang CQ, Deng J, Yan JC, Wang YJ, Zhou HD: Vascular risk aggravates the progression of Alzheimer's disease in a Chinese cohort. J Alzheimers Dis 2010;20:491-500.

-13 Solomon A, Kivipelto M, Wolozin B, Zhou J, Whitmer RA: Midlife serum cholesterol and increased risk of Alzheimer's and vascular dementia three decades later. Dement Geriatr Cogn Disord 2009;28: 75-80.

-14 Panza F, D’Introno A, Colacicco AM, Capurso C, Parigi AD, Capurso SA, Caselli RJ, Pilotto A, Scafato E, Capurso A, Solfrizzi V: Cognitive frailty: predementia syndrome and vascular risk factors. Neurobiol Aging 2006;27:933-940.

-15 Solfrizzi V, Panza F, Colacicco AM, D’Introno A, Capurso C, Torres F, Grigoletto F, Maggi S, Del Parigi A, Reiman EM, Caselli RJ, Scafato E, Farchi G, Capurso A: Vascular risk factors, incidence of MCI, and rates of progression to dementia. Neurology 2004;63:1882-1891.

-16 Li J, Wang YJ, Zhang M, Xu ZQ, Gao CY, Fang CQ, Yan JC, Zhou HD: Vascular risk factors promote conversion from mild cognitive impairment to Alzheimer disease. Neurology 2011;76:1485-1491.

-17 Larson EB, Wang L, Bowen JD, McCormick WC, Teri L, Crane P, Kukull W: Exercise is associated with reduced risk for incident dementia among persons 65 years of age and older. Ann Intern Med 2006;144:73-81.

- 18 Kemoun G, Thibaud M, Roumagne N, Carette P, Albinet C, Toussaint L, Paccalin M, Dugue B: Effects of a physical training programme on cognitive function and walking efficiency in elderly persons with dementia. Dement Geriatr Cogn Disord 2010;29:109-114.

-19 De Backer G, Ambrosioni E, Borch-Johnsen K, Brotons C, Cifkova R, Dallongeville J, Ebrahim S, Faergeman O, Graham I, Mancia G, Manger Cats V, Orth-Gomer K, Perk J, Pyorala K, Rodicio JL, Sans S, Sansoy V, Sechtem U, Silber S, Thomsen T, Wood D: European guidelines on cardiovascular disease prevention in clinical practice. Third Joint Task Force of European and Other Societies on Cardiovascular Disease Prevention in Clinical Practice. Eur Heart J 2003;24:16011610. 
Uemura et al.: Effects of Exercise Intervention on Vascular Risk Factors in Older Adults with Mild Cognitive Impairment: A Randomized Controlled Trial

-20 Tsuzuku S, Kajioka T, Endo H, Abbott RD, Curb JD, Yano K: Favorable effects of non-instrumental resistance training on fat distribution and metabolic profiles in healthy elderly people. Eur J Appl Physiol 2007;99:549-555.

-21 Williams AD, Almond J, Ahuja KD, Beard DC, Robertson IK, Ball MJ: Cardiovascular and metabolic effects of community based resistance training in an older population. J Sci Med Sport 2011;14: 331-337.

-22 Martins RA, Verissimo MT, Coelho e Silva MJ, Cumming SP, Teixeira AM: Effects of aerobic and strength-based training on metabolic health indicators in older adults. Lipids Health Dis 2010;9:76.

-23 Carvalho J, Marques E, Ascensao A, Magalhaes J, Marques F, Mota J: Multicomponent exercise program improves blood lipid profile and antioxidant capacity in older women. Arch Gerontol Geriatr 2010;51:1-5.

24 Morris JC: The Clinical Dementia Rating (CDR): current version and scoring rules. Neurology 1993; 43:2412-2414.

25 Schulz KF, Altman DG, Moher D, CONSORT Group: CONSORT 2010 statement: Updated guidelines for reporting parallel group randomised trials. BMJ 2010;340:c332.

-26 Carroll S, Tsakirides C, Hobkirk J, Moxon JW, Dudfield M, Ingle L: Differential improvements in lipid profiles and framingham recurrent risk score in patients with and without diabetes mellitus undergoing long-term cardiac rehabilitation. Arch Phys Med Rehabil 2011;92:1382-1387.

27 Thompson G: Which lipid fraction is the target and how often should this be monitored? Heart 2010; 96:413-414.

-28 Butland RJ, Pang J, Gross ER, Woodcock AA, Geddes DM: Two-, six-, and 12-minute walking tests in respiratory disease. Br Med J (Clin Res Ed) 1982;284:1607-1608.

-29 Nagai K, Yamada M, Tanaka B, Uemura K, Mori S, Aoyama T, Ichihashi N, Tsuboyama T: Effects of balance training on muscle coactivation during postural control in older adults: a randomized controlled trial. J Gerontol A Biol Sci Med Sci 2012;67:882-889.

-30 National Cholesterol Education Program (NCEP) Expert Panel on Detection, Evaluation, and Treatment of High Blood Cholesterol in Adults (Adult Treatment Panel III): Third Report of the National Cholesterol Education Program (NCEP) Expert Panel on Detection, Evaluation, and Treatment of High Blood Cholesterol in Adults (Adult Treatment Panel III) final report. Circulation 2002;106: 3143-3421.

-31 Kelley GA, Kelley KS, Tran ZV: Exercise, lipids, and lipoproteins in older adults: a meta-analysis. Prev Cardiol 2005;8:206-214

-32 Swardfager W, Herrmann N, Cornish S, Mazereeuw G, Marzolini S, Sham L, Lanctot KL: Exercise intervention and inflammatory markers in coronary artery disease: a meta-analysis. Am Heart J 2012;163:666-676.e1-e3.

-33 Kelley GA, Kelley KS: Effects of aerobic exercise on lipids and lipoproteins in adults with type 2 diabetes: a meta-analysis of randomized-controlled trials. Public Health 2007;121:643-655.

34 Kelley GA, Kelley KS: Aerobic exercise and lipids and lipoproteins in men: a meta-analysis of randomized controlled trials. J Mens Health Gend 2006;3:61-70.

- 35 Pescatello LS, Murphy D, Costanzo D: Low-intensity physical activity benefits blood lipids and lipoproteins in older adults living at home. Age Ageing 2000;29:433-439.

-36 Durstine JL, Grandjean PW, Davis PG, Ferguson MA, Alderson NL, DuBose KD: Blood lipid and lipoprotein adaptations to exercise: a quantitative analysis. Sports Med 2001;31:1033-1062.

-37 Yaffe K, Barrett-Connor E, Lin F, Grady D: Serum lipoprotein levels, statin use, and cognitive function in older women. Arch Neurol 2002;59:378-384.

-38 Reitz C, Tang MX, Luchsinger J, Mayeux R: Relation of plasma lipids to Alzheimer disease and vascular dementia. Arch Neurol 2004;61:705-714.

-39 Frisardi V, Solfrizzi V, Seripa D, Capurso C, Santamato A, Sancarlo D, Vendemiale G, Pilotto A, Panza F: Metabolic-cognitive syndrome: a cross-talk between metabolic syndrome and Alzheimer's disease. Ageing Res Rev 2010;9:399-417.

-40 Refolo LM, Malester B, LaFrancois J, Bryant-Thomas T, Wang R, Tint GS, Sambamurti K, Duff K, Pappolla MA: Hypercholesterolemia accelerates the Alzheimer's amyloid pathology in a transgenic mouse model. Neurobiol Dis 2000;7:321-331. 
Uemura et al.: Effects of Exercise Intervention on Vascular Risk Factors in Older Adults with Mild Cognitive Impairment: A Randomized Controlled Trial

-41 Roger VL, Go AS, Lloyd-Jones DM, Adams RJ, Berry JD, Brown TM, Carnethon MR, Dai S, de Simone G, Ford ES, Fox CS, Fullerton HJ, Gillespie C, Greenlund KJ, Hailpern SM, Heit JA, Ho PM, Howard VJ, Kissela BM, Kittner SJ, Lackland DT, Lichtman JH, Lisabeth LD, Makuc DM, Marcus GM, Marelli A, Matchar DB, McDermott MM, Meigs JB, Moy CS, Mozaffarian D, Mussolino ME, Nichol G, Paynter NP, Rosamond WD, Sorlie PD, Stafford RS, Turan TN, Turner MB, Wong ND, Wylie-Rosett J, American Heart Association Statistics Committee and Stroke Statistics Subcommittee: Heart disease and stroke statistics - 2011 update: a report from the American Heart Association. Circulation 2011;123:e18-e209.

-42 Lewington S, Whitlock G, Clarke R, Sherliker P, Emberson J, Halsey J, Qizilbash N, Peto R, Collins R: Blood cholesterol and vascular mortality by age, sex, and blood pressure: a meta-analysis of individual data from 61 prospective studies with 55,000 vascular deaths. Lancet 2007;370:1829-1839.

-43 Consensus conference. Lowering blood cholesterol to prevent heart disease. JAMA 1985;253:2080 2086.

-44 Nigam PK: Serum lipid profile: fasting or non-fasting? Indian J Clin Biochem 2011;26:96-97.

-45 Yu-Poth S, Zhao G, Etherton T, Naglak M, Jonnalagadda S, Kris-Etherton PM: Effects of the National Cholesterol Education Program's Step I and Step II dietary intervention programs on cardiovascular disease risk factors: a meta-analysis. Am J Clin Nutr 1999;69:632-646. 